\title{
Changes in gene expression following androgen receptor blockade is not equivalent to androgen ablation by castration in the rat ventral prostate
}

\author{
Anil M Limaye ${ }^{I}$, Irfan Asangani, Thyagarajan Kalyani and Paturu Kondaiah* \\ Department of Molecular Reproduction, Development and Genetics, Indian Institute of Science, Bangalore 560 012, India \\ ${ }^{1}$ Present address: Chromatin Biology Lab, Molecular Biology and Genetics Unit, \\ Jawaharlal Nehru Centre for Advanced Scientific Research, Jakkur, Bangalore 560 064, India \\ *Corresponding author (Fax, 91-80-2360 0999; Email, paturu@mrdg.iisc.ernet.in)
}

\begin{abstract}
Involution of the rat ventral prostate and concomitant modulation of gene expression post-castration is a welldocumented phenomenon. While the rat castration model has been extensively used to study androgen regulation of gene expression in the ventral prostate, it is not clear whether all the gene expression changes post-castration are due to androgen depletion alone. To obtain insights into this, we performed differential display reverse transcriptase polymerase chain reaction (DD-RT-PCR) which resulted in the identification of castration and/or flutamide-regulated genes in the rat ventral prostate. These include clusterin, methionine adenosyl transferase II $\alpha$, and prostate-specific transcripts such as PBPC1BS, S100RVP and A7. While clusterin, PBPC1BS and methionine adenosyl transferase II $\alpha$ are regulated by both castration and flutamide, S100 RVP and A7 are regulated by castration alone. Interestingly, we show that flutamide, unlike castration, does not induce apoptosis in the rat ventral prostate epithelium, which could be an underlying cause for the differential effects of castration and flutamide treatment. We propose that castration leads to enrichment and depletion of stromal and epithelial cell types, respectively, resulting in erroneous conclusions on some of the cell type-specific transcripts as being androgen regulated.
\end{abstract}

[Limaye A M, Asangani I, Kalyani T and Kondaiah P 2008 Changes in gene expression following androgen receptor blockade is not equivalent to androgen ablation by castration in the rat ventral prostate; J. Biosci. 33 209-220]

\section{Introduction}

Androgens play an important role in the development, growth and maintenance of differentiated functions of the prostate. Much of the current understanding of the role of androgens in the tissue homeostasis of the prostate is based on studies on the rat ventral prostate (RVP) following castration. Lee et al (1990) demonstrated that the adult RVP is a dynamic system in which cell death in the proximal epithelium balances out cell proliferation in the distal epithelium. Castration of adult male rats leads to a rapid reduction in serum androgens, and a collapse of this dynamic equilibrium results in rapid involution and loss of secretory activity of the ventral prostate. The process of involution is an active one involving a cascade of biochemical steps leading to programmed cell death of the glandular epithelial cells (Kerr and Searle 1973; Sandford et al 1984; Kyprianou and Isaacs 1988; English et al 1989). The glandular epithelial cells constitute about $85 \%$ of the RVP. By day 7 post-castration, loss of $70 \%$ of the glandular epithelial cells has been demonstrated (Kyprianou and Isaacs 1988; English et al 1989). These effects of castration on the RVP can be reversed by androgen supplementation, which leads to regrowth of the prostate and restoration of secretory activity (Coffey et al 1968; Wright et al 1999). Castration-induced programmed cell death in the RVP is accompanied by modulation of gene expression, which is also reversed by androgen supplementation. Thus, castration has been extensively used as a tool to study in vivo gene expression changes in the context of regression/ regrowth of the prostate and identification of androgen-

Keywords. Castration; DD-RT-PCR; flutamide; gene expression; rat ventral prostate

Abbreviations used: DD-RT-PCR, differential display reverse transcriptase polymerase chain reaction; DHT, dihydrotestosterone; MATII $\alpha$, methionine adenosyl transferase II $\alpha$; PBS, phosphate buffered saline; PKC, protein kinase C; RVP, rat ventral prostate 
regulated genes, which are of relevance for understanding (i) androgen-dependent and -independent growth of prostate cancer, and (ii) identification of diagnostic/prognostic and therapeutic targets for prostate cancer.

Till date, a plethora of androgen-regulated genes have been identified in the RVP using the castration model. However, very few studies have used flutamide as a tool to probe into androgen-regulated gene expression in the prostate. Although it is expected that castration and flutamide will exert similar effects on gene expression and physiology of the prostate, a few reports contrary to this have been published recently. Flutamide does not induce TRPM-2 mRNA (a testosterone-repressed transcript) in the RVP (Russo et al 1994). Conversely, Turner et al (2001) reported the inability of flutamide to block suppression of TRPM-2 by testosterone. However, in an independent study, Leger et al (1988) demonstrated induction of TRPM-2 following flutamide treatment in castrated rats receiving a maintenance dose of androgen. Castration and flutamide administration have been shown to have opposite effects on the expression of protein kinase C (PKC) isoforms in the RVP. While castration leads to reduced expression, flutamide has been shown to increase the levels of PKC isoforms (Montalvo et al 2002). In our laboratory, we had previously identified a few flutamide-regulated transcripts in the RVP. Interestingly, we found that castration had a similar or no effect on the expression of the flutamide-regulated transcripts (Limaye et al 2007), thus reiterating the disparity in the effects of castration and flutamide treatment as reported by other investigators. These intriguing observations warrant further investigation into the effects of castration and flutamide on gene expression, as they may provide useful insights into the androgen regulation of gene expression in the RVP.

Here, we present further insights into the differential effects of castration and flutamide treatment in the RVP. We analysed the effect of castration and flutamide treatment on expression levels of a few known and unknown transcripts identified by differential display reverse transcriptase polymerase chain reaction (DD-RT-PCR). Furthermore, we show that flutamide does not induce apoptosis of the RVP epithelium. Our data suggest that the observed regulation of genes following castration could be due in part to depletion of the epithelial compartment and not due to androgen regulation. This study clearly highlights the caveat in using the castration model as a means to identify androgenregulated genes.

\section{Methods}

\subsection{Animals}

Wistar male rats used in this study were obtained from the Central Animal Facility at the Indian Institute of Science.
The animals were 60-70 days old and maintained according to the guidelines of the institute with access to rat chow and water ad libitum.

\subsection{Hormonal manipulations}

Castrations were performed via the scrotal route under ether anaesthesia and the animals were maintained for 1 day (day 1 post-castration), 3 days (day 3 post-castration) and 5 days (day 5 post-castration). Sham-castrated animals maintained for 5 days (day 5 sham-castrated) served as controls. The castrated animals receiving testosterone replacement were given three intraperitoneal injections of testosterone propionate $(1 \mathrm{mg} / \mathrm{kg}$ body weight $)$ after day 2 , day 3 and day 4 post-castration. Flutamide was administered intraperitoneally in doses of $50 \mathrm{mg} / \mathrm{kg}$ body weight every 12 $\mathrm{h}$ for 5 days (day 5 flutamide). In experiments to study the effect of flutamide treatment on testosterone replacement, 5 doses of flutamide as mentioned above were administered to testosterone-replaced rats, each given every $12 \mathrm{~h}$, starting from $12 \mathrm{~h}$ after the first testosterone propionate injection (testosterone-replaced + flutamide-treated). In these experiments, castrated rats also received similar doses of flutamide at identical time points (day 5 castrated + flutamide-treated).

\subsection{RNA extraction}

RNA was extracted from frozen tissues using TRI Reagent (Sigma-Aldrich, USA) according to the manufacturer's instructions. The total RNA was further purified using the RNeasy Kit (Qiagen, GmbH, Germany). RNA concentration was estimated by measuring the absorbance at $260 \mathrm{~nm}$ and the quality was assessed by agarose-formaldehyde gel electrophoresis.

\section{$2.4 D D-R T-P C R$}

The DD-RT-PCR protocol described by Wan and Erlander (1997) was used with minor modifications. Briefly, $500 \mathrm{ng}$ of total RNA was reverse transcribed with anchored primer (table 1). The resultant cDNAs were diluted 20 times in water and $1 \mu 1$ was used for PCR using $500 \mathrm{ng}$ of anchored primer (corresponding primer used for cDNA synthesis) and $500 \mathrm{ng}$ of arbitrary primer (table 2) in the presence of $\alpha^{-32} \mathrm{P}$ dCTP. The PCR conditions were $94^{\circ} \mathrm{C}$ for $20 \mathrm{~s}, 42^{\circ} \mathrm{C}$ for $20 \mathrm{~s}$ and $72^{\circ} \mathrm{C}$ for $30 \mathrm{~s}$ for 40 cycles. Of the PCR product, $1 \mu 1$ was mixed with $1 \mu 1$ of sequencing loading dye $(95 \%$ formamide, $10 \mathrm{mM}$ EDTA, $0.1 \%$ xylene cyanol and $0.1 \%$ bromophenol blue), heated at $80^{\circ} \mathrm{C}$ for $5 \mathrm{~min}$, chilled on ice and resolved on a $6 \%$ polyacrylamide gel containing $7 \mathrm{M}$ urea, transferred onto $3 \mathrm{M}$ Whatman paper (3 MM CHR), 
Table 1. Sequences of the anchored primers

\begin{tabular}{|c|c|}
\hline Name & Primer sequence \\
\hline E1T12MA & 5'- CGGA ATTCGGTTTTTTTTTTTTVA -3' \\
\hline E1T12MC & 5'- CGGAATTCGGTTTTTTTTTTTTVC -3' \\
\hline E1T12MG & 5'- CGGA ATTCGGTTTTTTTTTTTTVG -3' \\
\hline E1T12MT & 5'- CGGA ATTCGGTTTTTTTTTTTTVT -3' \\
\hline
\end{tabular}

$\mathrm{V}=\mathrm{A}, \mathrm{G}$ or $\mathrm{C}$; sequence in bold italics is the EcoRI restriction site.

Table 2. Sequences of the arbitrary primers

\begin{tabular}{|c|c|}
\hline Name & Primer sequence \\
\hline AP1 & 5'- CGTGAATTCGAGCCAGCGAA -3' \\
\hline AP2 & 5'- CGTGAATTCGGACCGCTTGT -3' \\
\hline AP3 & 5'- CGT $\boldsymbol{G} \boldsymbol{A} \boldsymbol{A} \boldsymbol{T} \boldsymbol{T} \boldsymbol{C G A G G T G A C C G T ~ - 3 ' ~}$ \\
\hline AP4 & 5'- CGTGAATTCGGGTACTCCAC -3' \\
\hline AP5 & 5'- CGTGA ATTCGGTTGCGATCC -3' \\
\hline AP6 & 5'- CGTGAATTCGGCAATCGATG -3' \\
\hline AP7 & 5'- CGTGAATTCGCCGAAGGAAT -3' \\
\hline
\end{tabular}

Sequence in bold italics is the EcoRI restriction site.

dried under vacuum at $80^{\circ} \mathrm{C}$ and exposed to an X-ray film. Differentially expressed cDNAs were excised from the gel and eluted in $100 \mu \mathrm{l}$ of water by boiling for $15 \mathrm{~min}$. Following centrifugation at $10000 \mathrm{rpm}$ for $5 \mathrm{~min}$, the cDNA in the supernatant was amplified using the appropriate combination of anchored and arbitrary primers. The amplified cDNAs were cloned in pBluescript or pGEMTEasy vector prior to sequencing or sequenced directly using arbitrary primers with an automated sequencer (ABI).

\subsection{Northern blot analysis}

cDNAs were labelled with $\alpha{ }^{3}{ }^{32} \mathrm{P}$ dCTP (specific activity 3000 $\mathrm{Ci} / \mathrm{mmol}$, Perkin Elmer) using the Random Primer Labeling Kit (Bangalore Genei, India) and purified using SephadexG50 spin columns. Fifteen to $20 \mu \mathrm{g}$ of RNA was resolved on $1 \%$ agarose-formaldehyde gel and blotted onto a nylon membrane (Biodyne ${ }^{\circledR}$ B Membrane, Pall Corporation). The prehybridization, hybridization and washing steps were performed as described previously (Desai and Kondaiah 2000). For quantification of northern blots, the band intensities obtained for the various cDNAs were normalized against those obtained for $18 \mathrm{~S}$ rRNA. The normalized values obtained for day 5 sham-castrated controls were assigned the value of 1 or 100 , and those obtained for other treatments were plotted as fold induction or percentage of control. The quantifications have been graphically represented where bars represent mean $\pm \mathrm{SD}$. Data obtained from two animals, each from independent experiments, were used to calculate the mean and SD.

\subsection{Tissue fixation and sectioning}

Ventral prostates were fixed in 4\% paraformaldehyde for a period of $48 \mathrm{~h}$. The fixed tissues were washed thoroughly with water and gradually dehydrated, cleared and paraffin embedded using the standard protocol in an automated tissue processor TP1020 (Leica, Nussloch, Germany). Sections of 5-7 $\mu \mathrm{m}$ were cut and placed on glass slides. These were stored at $4^{\circ} \mathrm{C}$ until used for TUNEL assay and in situ hybridization analysis.

\subsection{TUNEL assay}

Sections were deparaffinized and rehydrated using a standard procedure. Endogenous peroxidase activity was blocked by incubating the slides in $0.6 \%$ hydrogen peroxide followed by treatment with $20 \mu \mathrm{g} / \mathrm{ml}$ proteinase $\mathrm{K}$ for 30 $\mathrm{min}$ at $37^{\circ} \mathrm{C}$. The slides were then incubated in $100 \mathrm{mM}$ glycine in phosphate buffered saline (PBS) for $10 \mathrm{~min}$ followed by PBS washes (3 times for 5 min each). Sections were then equilibrated with TdT reaction buffer for $20 \mathrm{~min}$ at $37^{\circ} \mathrm{C}$ followed by incubation for $90 \mathrm{~min}$ in $\mathrm{TdT}$ reaction buffer containing $10 \mu \mathrm{m}$ dATP, $5 \mu \mathrm{M}$ of biotin-16-dUTP and 8 units of TdT per section. The slides were washed in $1 \mathrm{X}$ $\mathrm{SSC}$ at room temperature for $15 \mathrm{~min}$ followed by washes in PBS (3 times for 5 min each). The sections were blocked with $0.2 \%$ blocking reagent (Boehringer Mannheim) and $0.05 \%$ Tween-20 in PBS for $30 \mathrm{~min}$. Sections were then treated with streptavidin-peroxidase conjugate (Bangalore Genei, 1:250 dilution) in blocking reagent for $2 \mathrm{~h}$. The excess conjugate was washed with PBS ( 3 times for $5 \mathrm{~min}$ each). Subsequently, the sections were exposed to $0.05 \%$ diaminobenzidine and $0.1 \%$ hydrogen peroxide in PBS until brown staining appeared. The sections were counterstained with methylene blue and mounted with $50 \%$ glycerol and observed under the microscope for the presence of TUNELpositive cells.

\subsection{In situ hybridization}

S100RVP cDNA was cloned in pBluescript (Stratagene) such that $\mathrm{T} 7$ and $\mathrm{T} 3$ polymerases generated the sense and antisense RNA, respectively. The plasmid was linearized with HindIII or XbaI, purified and used as a template in separate reactions for in vitro transcription with $\mathrm{T} 7$ and $\mathrm{T} 3$ RNA polymerases, respectively, using DIG-RNA labelling $\operatorname{mix}$ (Roche).

Deparaffinized and hydrated tissue sections were treated with $0.2 \mathrm{M} \mathrm{HCl}$ for $10 \mathrm{~min}$ and washed thrice in PBS for 
3 min each. The tissue was made permeable with $0.3 \%$ Triton $\mathrm{X}-100$ in PBS and subjected to proteinase $\mathrm{K}$ digestion and glycine treatment, as described in the previous section. The tissue sections were post-fixed in neutral buffered formalin and acetylated with $0.1 \mathrm{M}$ triethanolamine and $0.25 \%$ acetic anhydride for $10 \mathrm{~min}$. The slides were then dipped in ice-cold $20 \%$ glacial acetic acid for $10 \mathrm{~s}$ and immediately washed with deionized water for $5 \mathrm{~min}$. The sections were dehydrated in increasing grades of ethanol $(50 \%, 70 \%$ and absolute ethanol).

The sections were prehybridized for $30 \mathrm{~min}$ in hybridization buffer (6X SSC, 3\% SDS and 50\% deionized formamide containing $100 \mu \mathrm{g} / \mathrm{ml}$ yeast t-RNA) in a humidified chamber equilibrated with $50 \%$ formamide and maintained at $55^{\circ} \mathrm{C}$. The hybridization mixture containing DIG-labelled riboprobe in hybridization buffer was heated to $80{ }^{\circ} \mathrm{C}$ for $5 \mathrm{~min}$, placed on the sections (2-5 ng of riboprobe per section), covered with glass cover slips and the slides were immediately transferred to the humidified chamber maintained at $55^{\circ} \mathrm{C}$. Hybridization was carried out for $18 \mathrm{~h}$.

After the hybridization, the cover slips were removed in $2 \mathrm{X} \mathrm{SSC}$ and the slides were washed with $1 \mathrm{X} \mathrm{SSC} /$ $0.1 \%$ SDS twice for $5 \mathrm{~min}$ each. This was followed by two high-stringency washes at $55^{\circ} \mathrm{C}$ for $10 \mathrm{~min}$ each. The non-specifically bound RNA probe was digested with 10 $\mu \mathrm{g} / \mathrm{ml}$ RNAse A in $4 \mathrm{X} \mathrm{SSC}$ at $37^{\circ} \mathrm{C}$ for $30 \mathrm{~min}$. The slides were again rinsed in $2 \mathrm{X}$ SSC followed by high-stringent washes with $0.2 \mathrm{XSC} / 0.1 \% \mathrm{SDS}$, twice for $10 \mathrm{~min}$ each. The sections were blocked with blocking solution containing $0.2 \%$ blocking reagent (Boehringer Mannheim) and $0.05 \%$ Tween-20 in PBS for a minimum of $2 \mathrm{~h}$. The blocking solution was removed and $50 \mu 1$ of alkaline phosphatase-conjugated anti-DIG Fab fragments (diluted 1: 1000 in blocking solution) was applied to each section and incubated at room temperature for $2 \mathrm{~h}$. Excess antibody was washed with PBS and the sections were exposed to NBT/ BCIP substrate until specific staining was observed with minimum background. The reaction was stopped by dipping the slides in $10 \mathrm{mM}$ Tris and $1 \mathrm{mM}$ EDTA (pH 7.6), rinsed in water and counterstained with methyl green. The sections were mounted with $50 \%$ glycerol, and observed under the microscope and photographed.

\section{Results}

\section{$3.1 \quad D D-R T-P C R$}

We performed DD-RT-PCR analysis of the total RNA isolated from the ventral prostates of day 5 sham-castrated, day 5 castrated and day 5 flutamide-treated rats. Using a combination of anchored and arbitrary primers (tables 1 and 2) several differentially expressed transcripts were observed. Figure 1 shows differentially expressed transcripts along with two transcripts (A4 and A8; figure 1), which were not differentially expressed in castrated and flutamide-treated RVPs. These transcripts were re-amplified and either directly sequenced using the arbitrary primers or cloned into pBluescript or pGEMT-Easy vector before sequencing. Table 3 shows the identities of only the differentially regulated transcripts obtained using BLAST (Altschul et al 1990). We could not clone the intact A7 fragment but, surprisingly, after ligation of A7 and screening for recombinants, we obtained two clones with inserts of unexpected sizes designated as A7.2 and A7.3. These were sequenced and found to contain inserts corresponding to sialic acid synthase and S100RVP, respectively. However, sequencing of the A7 PCR product and a search for identical sequences in the existing database with BLAST (Altschul et al 1990) revealed its identity to a human sequence containing

Table 3. Identities and nature of regulation of differentially regulated fragments obtained by differential display reverse transcriptase polymerase chain reaction (DD-RT-PCR)

\begin{tabular}{llllll}
\hline Fragment & Regulation & $\begin{array}{l}\text { Sequenced } \\
\text { clone/fragment }\end{array}$ & Acc. No. & $\begin{array}{l}\text { Gene name } \\
\text { (\% identity) }\end{array}$ & Gene name (\% identity) \\
\hline A1 & DOWN & ND & Clone A1.2 & BK000198 & Rat PBPC1BS mRNA (98\%) \\
A3 & UP & UP & A3 PCR pdt & AK049455 & Mouse 7-day embryo whole body cDNA \\
A5 & UP & UR & A5 PCR pdt & BC062394 & Rat methionine adenosyl transferase II $\alpha$ mRNA \\
A6 & UP & UP & Clone A6.3 & BC061534 & Rat clusterin mRNA (100\%) \\
A7 & DOWN & DOWN & A7 PCR pdt & AL031073 & HS142F18 human DNA sequence from clone \\
& & & & RP1142F18 on Xq26.3 27.2 chromosome, \\
& & & Clontains MAGEE1 melanoma antigen (99\%) & Rat sialic acid synthase mRNA (100\%) \\
& & & XM_216398 & Rat S100 calcium-binding protein ventral \\
& & & Clone A7.3 & NM_176076 & \\
\end{tabular}

ND, not determined. 


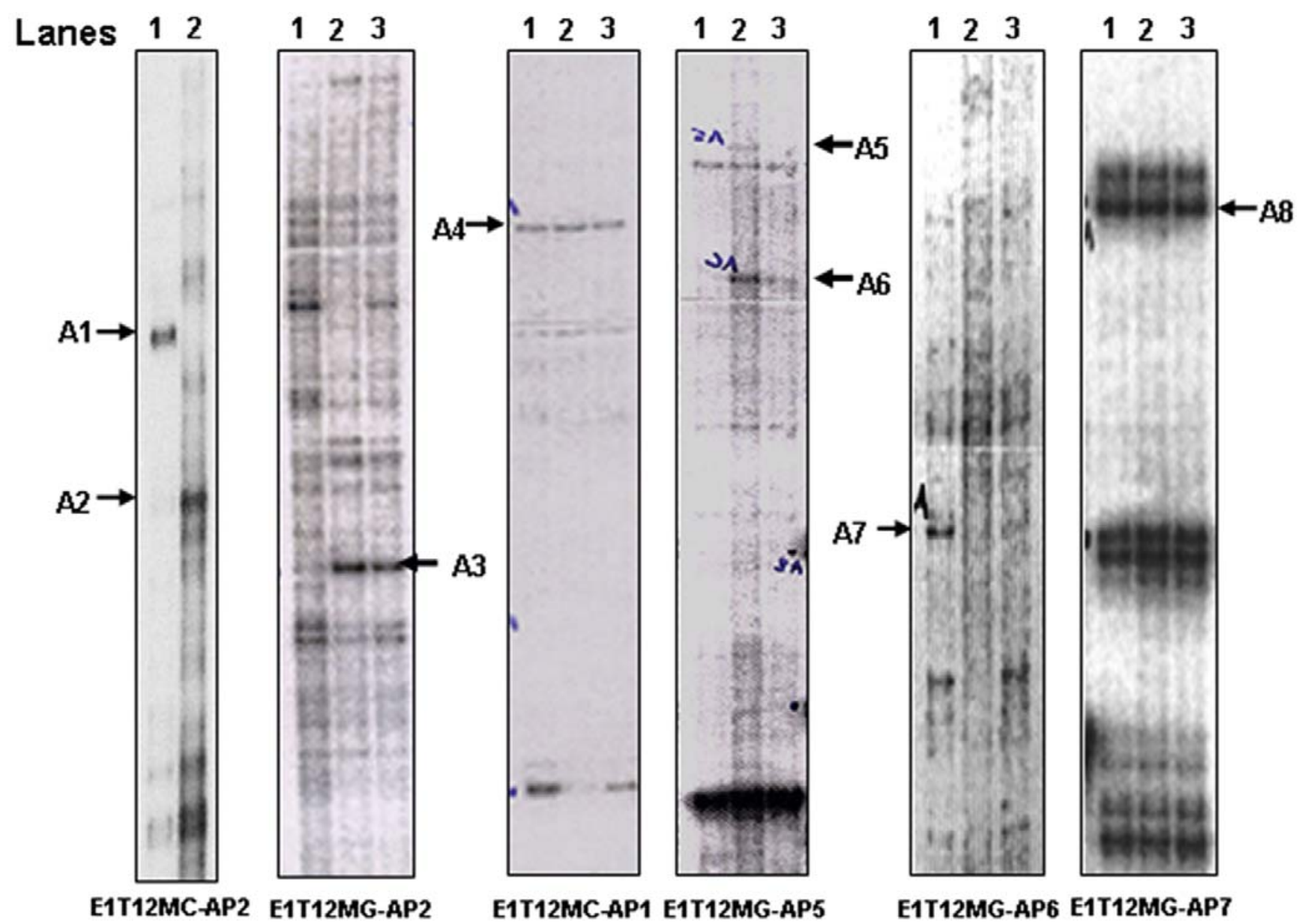

Figure 1. DD-RT-PCR analysis of the differentially expressed transcripts in the ventral prostates of sham-operated, castrated and flutamide-treated rats. The panels show differentially expressed transcripts obtained with combinations of anchored and arbitrary primers indicated at the bottom of each panel. The primer sequences are shown in tables 1 and 2. The differentially expressed transcripts (A1, A2, A3, A5, A6 and A7) and two transcripts whose expressions remain unchanged (A4 and A8) are indicated by arrows. Lanes: 1. day 5 shamcastrated, 2. day 5 castrated, 3. day 5 flutamide-treated.

MAGEE1 melanoma antigen and no similarity was found with the existing sequences in the rat database. Here we refer to this transcript as A7 mRNA. Among several novel genes, we identified clusterin (a known androgen-repressed gene in RVP), which was induced upon castration and flutamide treatment (table 3 ).

\subsection{Effect of castration and flutamide treatment on} clusterin and methionine adenosyl transferase II $\alpha$ mRAs

The expression of clusterin mRNA was enhanced in the RVP at day 1 , day 3 and day 5 post-castration. This effect of androgen withdrawal was reversed following supplementation with testosterone propionate. Flutamide treatment also caused a substantial increase in the clusterin mRNA levels, albeit at much lower levels than with castration. A $27.43 \pm 3$.9-fold induction was observed on castration as compared with 10.96 \pm 4.0 on flutamide treatment (mean $\pm \mathrm{SD}, N=2$, figure 2). In similar experiments the regulation of methionine adenosyl transferase II $\alpha$ (MATII $\alpha$ ) was also studied. Contrary to only one transcript of MATII $\alpha$ reported in the literature (Huang et al 1998), we observed two transcripts (approximately 3.4 and $3.0 \mathrm{~kb}$ ). The level of the higher molecular weight transcript was increased by day 3 post-castration and appeared to fall at day 5 post-castration to levels seen in sham-operated and testosterone-replaced animals. On the other hand, the low molecular weight transcript showed a gradual decrease from day 1 to day 5 post-castration, which was partially restored on testosterone replacement. Flutamide treatment enhanced the levels of the higher molecular weight transcript and moderately decreased the levels of the lower molecular weight transcript (figure 2). 
A

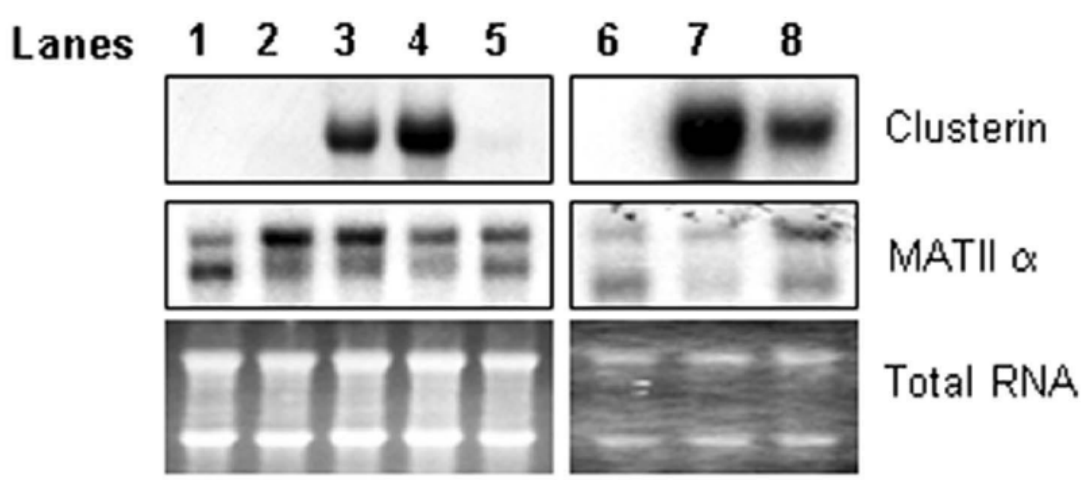

B

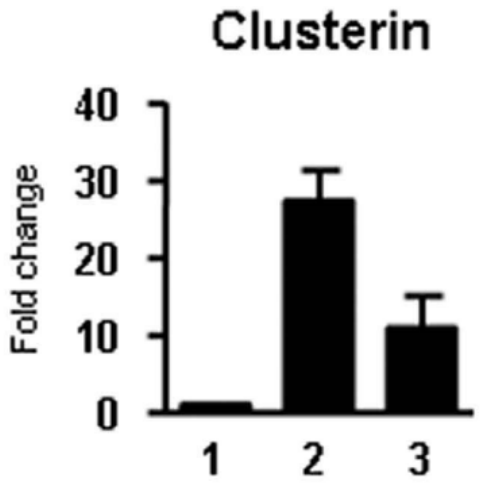

Figure 2. Regulation of clusterin and MATII $\alpha$ mRNA. (A) Time course of the modulation of gene expression following castration (lanes 1-5) and comparative analysis of the effects of castration and flutamide treatment (lanes 6-8). Lanes: 1. day 5 sham-castrated, 2. day 1 castrated, 3. day 3 castrated, 4. day 5 castrated, 5. testosterone-replaced, 6. day 5 sham-castrated, 7. day 5 castrated, 8 . day 5 flutamidetreated. (B) Graphical representation showing the fold change of clusterin mRNA expression following castration and flutamide treatment. Bars represent mean $\pm \mathrm{SD}(N=2)$. Bars: 1. day 5 sham-castrated, 2. day 5 castrated, 3. day 5 flutamide-treated.

\subsection{Effect of castration and flutamide treatment on the prostate-specific PBPC1BS, A7 and S100RVP mRNA transcripts}

Castration led to a dramatic fall in the steady-state expression of PBPC1BS mRNA to levels beyond detection at day 3 post-castration. Testosterone replacement restored PBPC1BS mRNA to a near-normal level (figure 3A). Using the A7 reamplified cDNA as a radiolabelled probe, we detected a transcript of approximately $1.7 \mathrm{~kb}$, which was abundantly expressed in the intact RVP. Castration led to a dramatic fall in the steady-state level of the A7 mRNA transcript, which was reversed by testosterone replacement. S100RVP also exhibited a similar pattern of regulation by castration and testosterone replacement (figure 3A). The kinetics of downregulation of the A7 and PBPC1BS transcripts were determined. PBPC1BS mRNA appeared to decrease more rapidly than A7. At day 1 post-castration, PBPC1BS mRNA was reduced to $18.31 \pm 8.2 \%$ of the control (mean $\pm \mathrm{SD}, N=2$ ) as opposed to $80.96 \pm 18.01 \%$ in the case of $\mathrm{A} 7$ (mean $\pm \mathrm{SD}, N=2$ ) (figure 3B). The castration data suggest that PBPC1BS, S100RVP and A7 transcripts are androgen-regulated in the RVP. In order to probe further into the regulation of these genes by androgens, the effect of flutamide treatment on intact rats was studied. Flutamide administration caused a marked reduction in the steadystate level of PBPC1BS mRNA (figure 3C). Surprisingly, the expression of A7 and S100RVP mRNAs remained unchanged upon flutamide treatment (figure 3C, D). A survey of the published literature revealed that PBPC1BS belongs to a large family of proteins called the secretoglobin family and is positioned close to RnPBPC1 and RnPBPC2 (coding for the $\mathrm{C} 1$ and $\mathrm{C} 2$ components of prostatic steroidbinding proteins, respectively) in a dendrogram showing the relatedness among members of this family (Reynolds et al 2002). These data suggested that the expression of PBPC1BS could be prostate-specific. The mRNA expression of PBPC1BS by northern blot using total RNA isolated from various adult rat tissues revealed its prostate-specific expression (figure $3 \mathrm{E}$ ). The A7 transcript was also found to be prostate-specific (figure 3E).

\subsection{Effect of flutamide on the RVP epithelium}

In order to assess the apoptotic activity in the RVP following castration and flutamide treatment, in situ detection of apoptosis (TUNEL assay) was performed. Interestingly, there was almost complete absence of TUNEL-positive nuclei in ventral prostate sections of flutamide-treated rats (figure 4). In contrast, ventral prostate sections of castrated rats showed TUNEL-positive nuclei. This suggests that flutamide does not induce apoptosis in the RVP.

\section{5 mRNA in situ hybridization analysis of S100RVP}

Downregulation of the S100RVP and A7 transcripts by castration but not by flutamide, coupled with the absence of apoptotic activity following flutamide treatment, suggested that the regulation of these mRNAs could only be apparent 
A
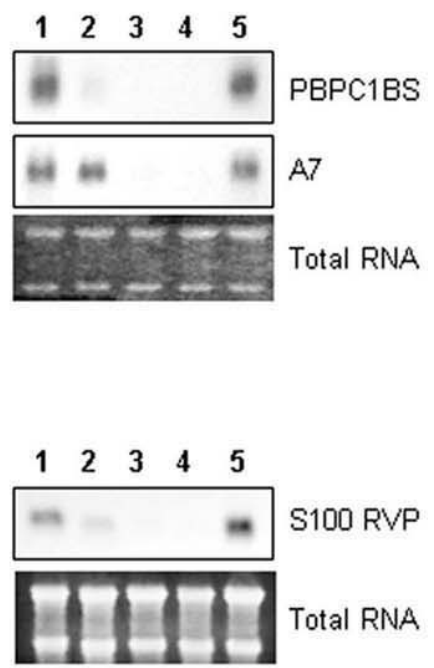

C
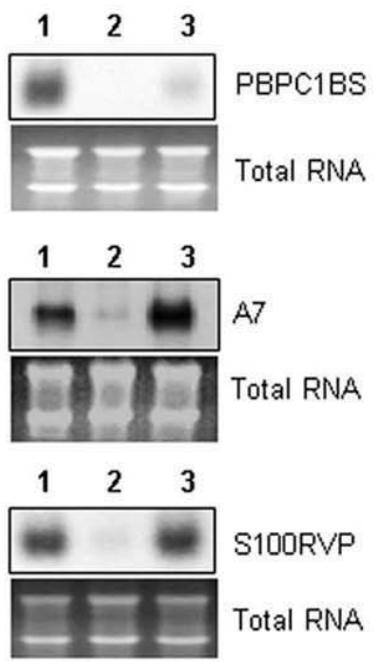

B

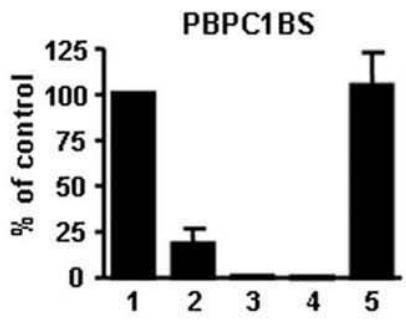

A7
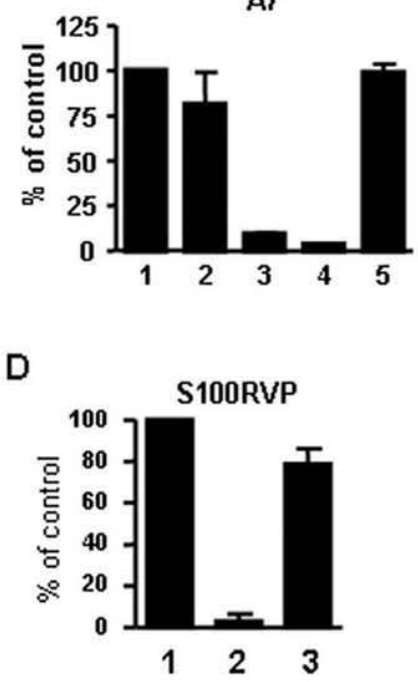

A7

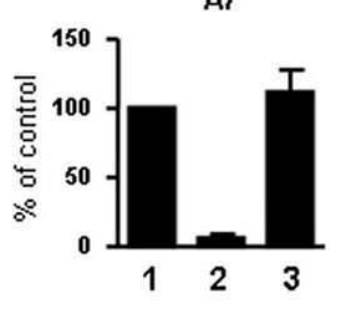

E
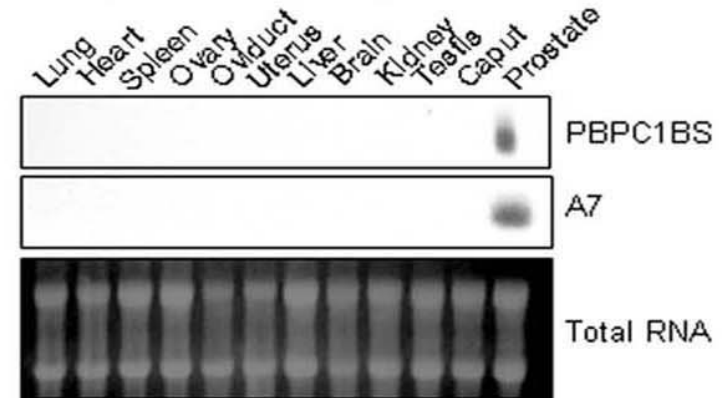

Total RNA

Figure 3. Effect of castration and flutamide treatment on the expression of PBPC1BS, A7 and S100RVP transcripts. (A) Time course of modulation of mRNA expression analysed by northern blotting. (B) Graphical representation of the change in expression of A7 and S100RVP post-castration. Bars represent mean $\pm \mathrm{SD}(N=2)$. Lanes and bars for $\mathbf{A}$ and $\mathbf{B}: \mathbf{1}$. day 5 sham-castrated, 2 . day 1 castrated, 3. day 3 castrated, 4. day 5 castrated, 5. testosterone replaced. (C) Comparative analysis of the effect of castration and flutamide treatment by northern blot. (D) Graphical representation of S100RVP and A7 mRNA expressions following castration and flutamide treatment. The indicated genes are shown beside each panel of northern blots. Bars represent mean \pm SD $(N=2)$. Lanes and bars for $\mathbf{C}$ and $\mathbf{D}$ : $\mathbf{1}$. day 5 sham-castrated, 2. day 5 castrated, 3. day 5 flutamide-treated. E. Prostate-specific expression of PBPC1BS mRNA and A7 transcript. 

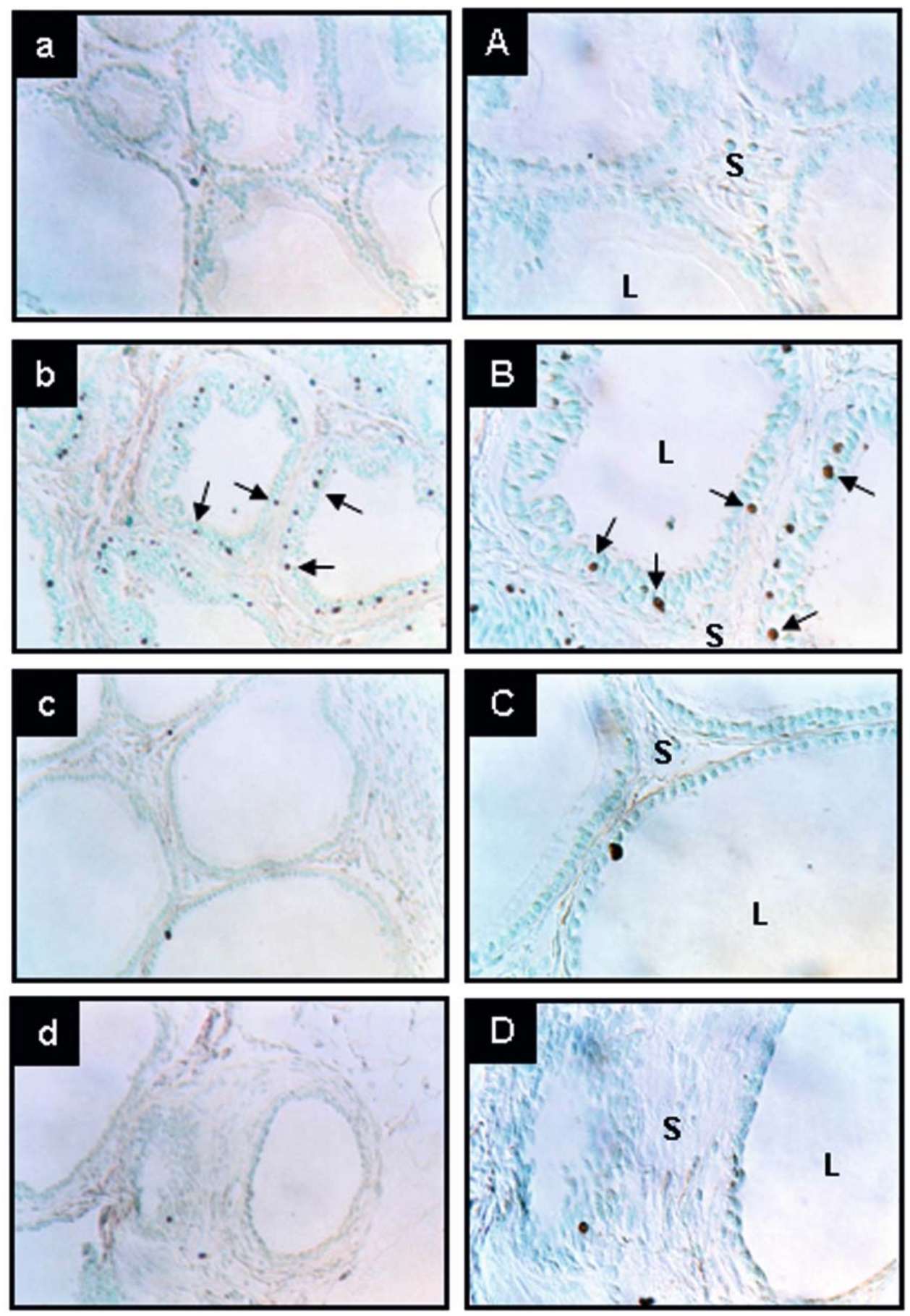

Figure 4. In situ detection of DNA fragmentation using TUNEL assay. (a,A) day 5 sham-castrated, (b,B) day 5 castrated, (c,C) day 5 flutamide-treated, (d,D) testosterone-replaced. Images are taken with 20X objective in $\mathbf{a}, \mathbf{b}, \mathbf{c}$ and $\mathbf{d}$, and with $40 \mathrm{X}$ objective in $\mathbf{A}, \mathbf{B}, \mathbf{C}$ and D. Arrows indicate apoptotic nuclei. S, stroma; L, lumen.

due to depletion of the majority of prostate epithelial cells at day 5 post-castration. This would be possible if S100RVP was localized to the glandular epithelial cells of the prostate. To test this, mRNA in situ hybridization using a DIGlabelled S100RVP antisense riboprobe was carried out. As shown in figure 5, S100RVP mRNA was detected only in the glandular epithelial cells, which was lost on castration and restored with testosterone supplementation. In agreement with the data of northern blot, flutamide treatment did not affect the epithelial expression of S100RVP. 

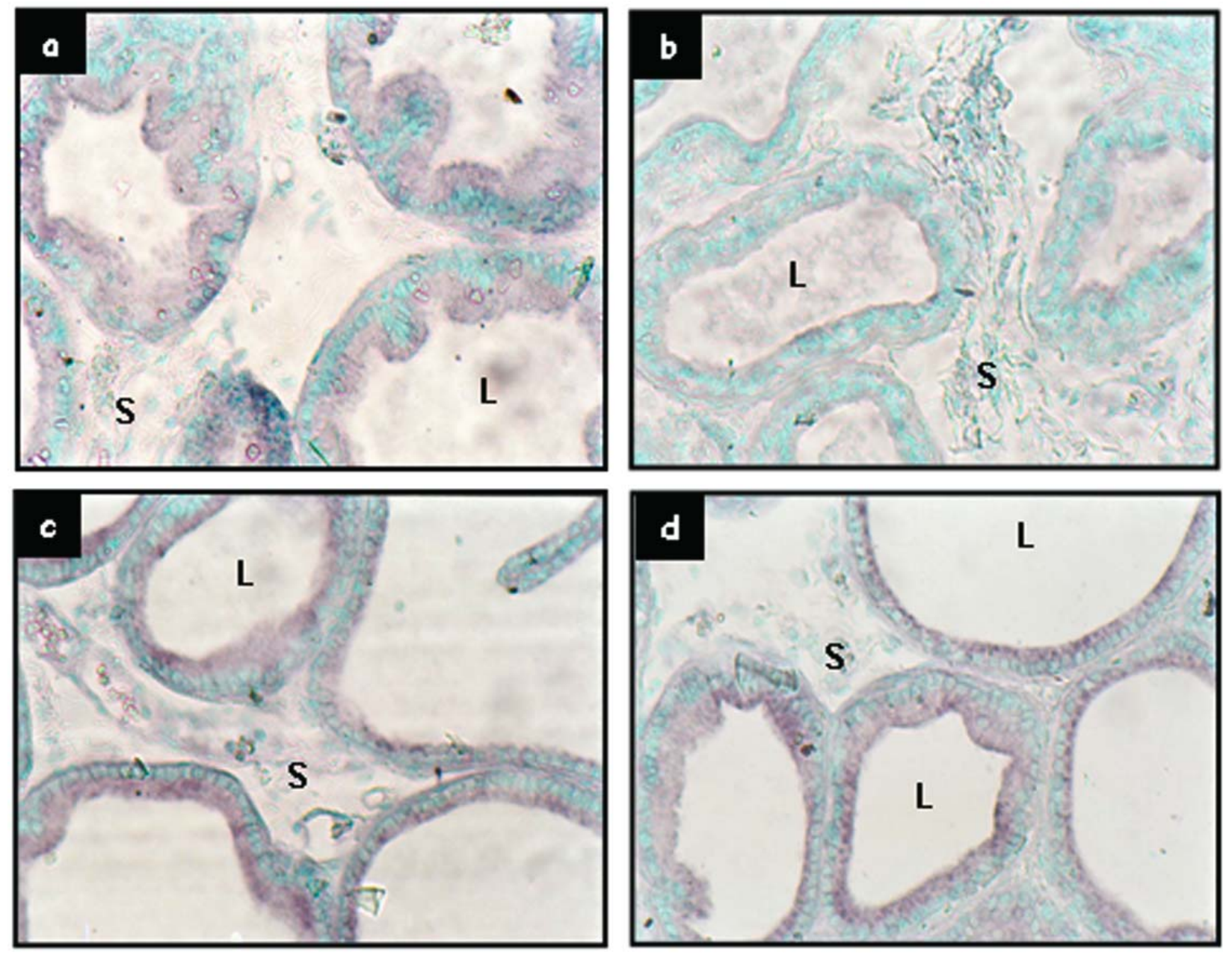

Figure 5. In situ hybridization analysis of the expression of S100RVP mRNA. a, day 5 sham-castrated; b, day 5 castrated; c, day 5 flutamide-treated; d, testosterone-replaced. S, stroma; L, lumen

\subsection{Effect of flutamide on testosterone-mediated reversal of castration effects}

Experiments discussed so far to study the effect of flutamide involved analysis of gene expression following administration of flutamide to intact animals. Testosterone supplementation to castrated rats not only causes reproliferation of prostate epithelial cells but also induces and suppresses androgen-induced and androgen-repressed genes respectively. The ability of flutamide to block the testosterone-mediated reversal of castration effects on gene expression was also evaluated. For this purpose, animals were castrated and given intraperitoneal injections of flutamide, testosterone propionate or both. Castrated control animals received the vehicle alone. The induction of prostatein $\mathrm{C} 1 \mathrm{mRNA}$ (a known androgen-induced gene) and PBPC1BS mRNA by testosterone supplementation to castrated animals was blocked by flutamide. Flutamide also blocked the suppression of clusterin by testosterone. Interestingly, although as shown previously, flutamide did not have any effect on A7 and S100RVP mRNA when injected into intact rats, it blocked the reappearance of A7 and S100RVP mRNAs by testosterone replacement (figure $6)$.

\section{Discussion}

Despite the widespread use of flutamide for the treatment of prostate cancer, its effect on the physiology of the prostate has hardly been studied. A few independent research groups have studied the effect of flutamide on gene expression in the RVP. These studies have revealed a differential effect of flutamide on gene expression compared with castration 

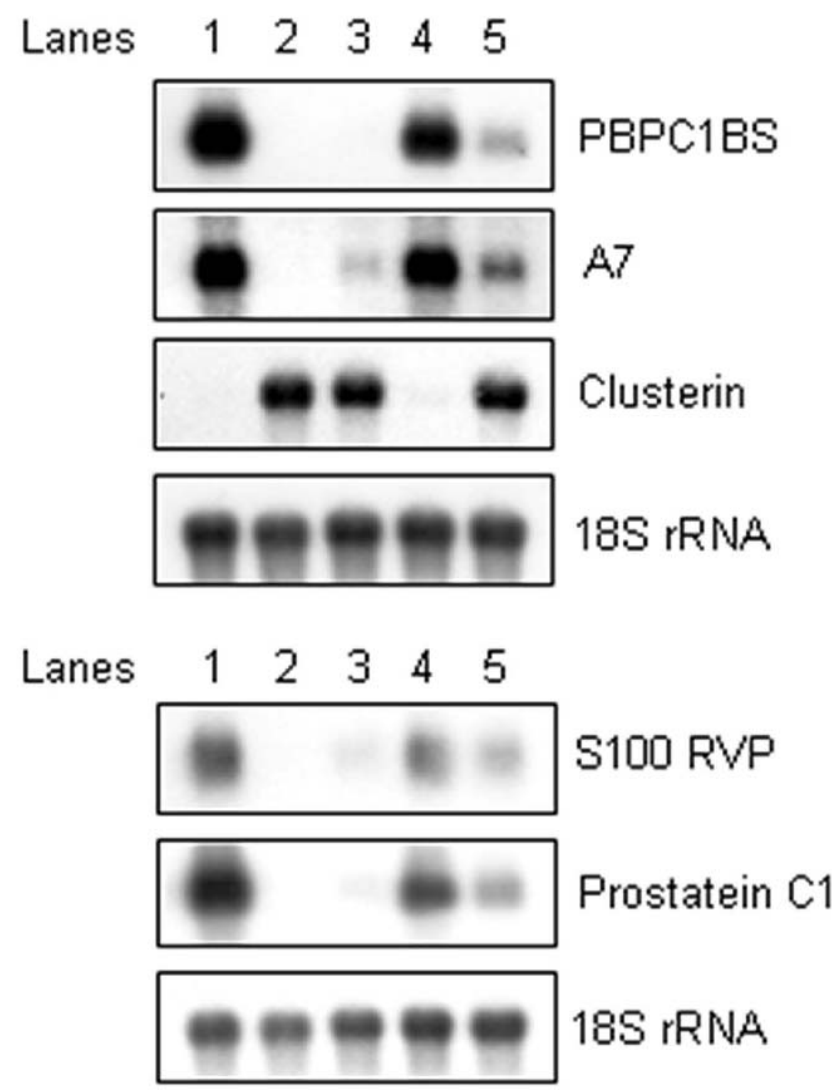

Figure 6. Effect of flutamide on reversal of castration effects by testosterone. Lanes: 1. control (intact rat ventral prostate), 2. day 5 castrated, 3 . day 5 castrated + flutamide-treated, 4 . testosteronereplaced, $\mathbf{5}$. testosterone-replaced + flutamide treated.

(Russo et al 1994; Turner et al 2001; Leger et al 1988; Montalvo et al 2002). Given the fact that flutamide is an androgen receptor antagonist, the question as to why castration and flutamide treatment should exert differential effects has not been addressed. The present study offers a possible explanation for the observed differential effects of castration and flutamide treatment in the RVP.

We have demonstrated differential expression patterns of transcripts identified by DD-RT-PCR following castration and flutamide treatment in the RVP. We have shown that the mRNA levels of clusterin, a known androgen-repressed gene, was increased by flutamide treatment, albeit to a much lesser extent compared with castration. The steady-state level of PBPC1BS mRNA, a prostate-specific transcript, was decreased by both castration and flutamide treatment. These findings suggest that the effects of androgen on PBPC1BS and clusterin are mediated via the androgen receptor. On the other hand, while expression of A7 and S100RVP was severely decreased to levels beyond detection at day 5 post-castration, they were largely unaffected by flutamide treatment. To our knowledge, this is the first report on transcripts that are downregulated by castration but not by flutamide treatment. Such differential effects of castration are inconsistent with the well-established idea of flutamide as an androgen receptor antagonist.

Based on the published data on the effects of antiandrogens on androgen receptor function and localization, one may think of several possibilities for the differential effects of castration and flutamide treatment. Antiandrogens have been shown to inhibit androgen receptor-responsive gene activation despite promoting androgen receptor nuclear import and DNA binding (Kemppainen et al 1992; Jenster et al 1993; Warriar et al 1993; Masiello et al 2002). Interestingly, partial activation of the androgen receptor by androgen-receptor antagonists such as flutamide and cyproterone acetate has also been demonstrated. Recently, Nguyen et al (2007) showed agonistic activity of flutamide in neurons, which was androgen receptor dependent. Similar agonistic activities of flutamide and other antiandrogens have been reported in several studies (Peterziel et al 1999; Evangelou et al 2000; Zhu et al 1999). Both agonistic and antagonistic effects are also shown by selective oestrogen receptor modulators (Gustafsson 1998). Thus, it is possible that flutamide assembles a transcriptionally active receptor on some while assembling a transcriptionally inactive receptor on other promoters, depending perhaps on the coactivators/corepressors that these complexes recruit. In a previous report, we showed that flutamide increases the steady-state mRNA expression of pumilio 1 in the RVP while castration has no effect (Limaye et al 2007). Possibly, the androgen receptor-independent actions of flutamide may be the underlying cause of the observed differential effects of castration and flutamide treatment. In this study, we have clearly demonstrated that flutamide does not induce apoptosis of the RVP epithelium. We hypothesized that the differential effect of castration and flutamide on the integrity of the RVP epithelium could be the underlying cause for the observed differential effects. In the following sections we discuss the supporting evidence for such a hypothesis.

The glandular epithelium comprises $85 \%$ of the cells in the RVP. Castration leads to apoptosis of the glandular epithelial cells causing severe depletion of the epithelial cell compartment (Kyprianou and Isaacs 1988; English et al 1989). Hence, a gene represented only in the epithelial compartment would be observed as downregulated by castration merely due to its expression in the epithelium, irrespective of whether or not it is regulated by androgen. We observed a complete absence of TUNEL-positive nuclei in the ventral prostates of flutamide-treated rats compared with those who underwent castration. Hence, the observed differential regulation of PBPC1BS, S100RVP and A7 could be a manifestation of the differences in integrity of 
the prostate epithelium following castration and flutamide treatment. We proposed that S100RVP and A7 transcripts are epithelial-specific genes, which may not truly represent androgen-regulated genes in the RVP and whose expression depends upon the integrity of the prostate epithelium. Evidence supporting this is the clear epithelial localization of S100RVP detectable in control, testosterone-replaced and flutamide-treated rats, but not in castrated rats. The other evidence for this is the kinetics of downregulation of the PBPC1BS and A7 mRNA transcripts following castration. Castration causes lowering of intraprostatic dihydrotestosterone (DHT) to levels below 5\% of the control by $12-24 \mathrm{~h}$ post-castration (Kyprianou and Isaacs 1988). However, apoptotic activity at day 1 post-castration is very low. In these conditions of very low prostatic DHT and low apoptotic activity at day 1 post-castration, PBPC1BS mRNA levels are reduced to $20 \%$ of the control, whereas A7 transcripts are reduced to only $80 \%$ of the control. A marked reduction in the A7 transcript level is observed only when peak apoptotic activity has set in at around day 3 postcastration. This suggests that the reduction of PBPC1BS mRNA is associated with the loss of testosterone, whereas the reduction of $\mathrm{A} 7$ transcripts is associated with the loss of epithelial cells. PBPC1BS, whose expression is also reduced by flutamide treatment, may represent a gene that is truly androgen regulated.

Adult rats exposed to flutamide in utero have been shown to exhibit severely compromised prostate growth and differentiation in a dose-dependent manner (ImperatoMcGinley et al 1992), indicating the importance of the androgen receptor in epithelial proliferation during development. The phenomenon of stroma-directed epithelial proliferation recurs during regrowth of the prostatic epithelium following testosterone supplementation of castrated rats. Testosterone-induced increase in ventral prostate weight in castrated rats was shown to be blocked by flutamide (Nellemann et al 2005), indicating the ability of flutamide to block reproliferation of the epithelium. In the present study, the effect of flutamide on reversal by testosterone of the effects of castration was evaluated. Flutamide administered to intact rats did not have any effect on S100RVP and A7 transcript levels. However, the reappearance of these transcripts following testosterone supplementation of castrated animals was blocked by flutamide treatment. This can be explained by the fact that flutamide blocks reproliferation of the epithelium induced by testosterone replacement, and that A7 and S100RVP are epithelial-specific genes. This in turn supports the view that the expression of S100RVP and A7 in the RVP depends on the presence of intact epithelium and that an epithelialspecific gene observed as downregulated by castration at the whole prostate level need not necessarily be an androgenregulated gene.
The data presented in this paper clearly demonstrate that castration and flutamide treatment have differential effects on gene expression. This study highlights the caveat in the widely used models of castration and testosterone replacement in identification of androgen-regulated genes. We conclude that interpretation of genes as androgen regulated in the RVP based solely on the effects of castration and testosterone replacement could be misleading. This obviously has a lot of bearing with regard to the search for novel androgen-regulated genes as therapeutic targets or diagnostic markers for prostate carcinoma using the RVP model.

\section{Acknowledgements}

We thank Rajnish P Rao and Kalika Prasad for their help with in situ hybridization protocols. We thank the staff of the Central Animal Facility at the Indian Institute of Science for the supply of animals. This work was funded by the Department of Biotechnology, New Delhi. Infrastructure support from the Department of Science and Technology, Indian Council of Medical Research and University Grants Commission, New Delhi, is acknowledged.

\section{References}

Altschul S F, Gish W, Miller W, Myers E W and Lipman D J 1990 Basic local alignment search tool; J. Mol. Biol. 215 403-410

Coffey D S, Shimazaki J and Williams-Ashman H G 1968 Polymerization of deoxyribonucleotides in relation to androgeninduced prostatic growth; Arch. Biochem. Biophys. 124 184-198

Desai K V and Kondaiah P 2000 Androgen ablation results in differential regulation of transforming growth factor-beta isoforms in rat male accessory sex organs and epididymis; J. Mol. Endocrinol. 24 253-260

English H F, Kyprianou N and Isaacs J T 1989 Relationship between DNA fragmentation and apoptosis in the programmed cell death in the rat prostate following castration; Prostate $\mathbf{1 5}$ 233-250

Evangelou A, Jindal S K, Brown T J and Letarte M 2000 Downregulation of transforming growth factor $\beta$ receptors by androgen in ovarian cancer cells; Cancer Res. 60 929-935

Gustafsson J A 1998 Therapeutic potential of selective estrogen receptor modulators; Curr. Opin. Chem. Biol. 2 508-511

Huang Z Z, Mao Z, Cai J and Lu S C 1998 Changes in methionine adenosyltransferase during liver regeneration in the rat; $\mathrm{Am}$. J. Physiol. 275 (1 Pt 1) G14-G21.

Imperato-McGinley J, Sanchez R S, Spencer J R, Yee B and Vaughan E D 1992 Comparison of the effects of the 5 alphareductase inhibitor finasteride and the antiandrogen flutamide on prostate and genital differentiation: dose-response studies; Endocrinology 131 1149-1156

Jenster G, Trapman J and Brinkmann A O 1993 Nuclear import of human androgen receptor; Biochem. J. 293 761-768 
Kemppainen J A, Lane M V, Sar M and Wilson E M 1992 Androgen receptor phosphorylation, turnover, nuclear import and transcriptional activation; J. Biol. Chem. 267 968-974

Kerr J F and Searle J 1973 Deletion of cells by apoptosis during castration-induced involution of the rat prostate; Virchows Arch. B Cell. Pathol. 13 87-102

Kyprianou N and Isaacs J T 1988 Activation of programmed cell death in the rat ventral prostate after castration; Endocrinology 122 552-562

Lee C, Sensibar J A, Dudek S M, Hiipakka R A and Liao S T 1990 Prostatic ductal system in rats: regional variation in morphological and functional activities; Biol. Reprod. 43 1079-1086

Leger J G, Le Guellec R and Tenniswood M P 1988 Treatment with antiandrogens induces an androgen-repressed gene in the rat ventral prostate; Prostate 13 131-142

Limaye A M, Asangani I, Bora N and Kondaiah P 2007 Novel flutamide regulated genes in the rat ventral prostate: differential modulation of their expression by castration and flutamide treatments; Asian J. Androl. 9 801-808

Masiello D, Cheng S, Bubley G J, Lu M L and Balk S P 2002 Bicalutamide functions as an androgen receptor antagonist by assembly of a transcriptionally inactive receptor; J. Biol. Chem. $27726321-26326$

Montalvo L, Sanchez-Chapado M, Prieto J C and Carmena M J 2002 Regulation of the expression of protein kinase C isoenzymes in rat ventral prostate: effects of age, castration and flutamide treatment; Life Sci. 71 2257-2266

Nellemann C, Dalgaard M, Holst B, Bonefeld-Jorgensen E C and Vinggaard A M 2005 Gene expression changes in rat prostate after activation or blocking of the androgen and estrogen receptor; Mol. Cell. Endocrinol. 237 25-35

Nguyen T V, Yao M and Pike C J 2007 Flutamide and cyproterone acetate exert agonist effects: induction of androgen receptordependent neuroprotection; Endocrinology 148 2936-2943
Peterziel H, Mink S, Schonert A, Becker M, Klocker H and Cato A C 1999 Rapid signalling by androgen receptor in prostate cancer cells; Oncogene 18 6322-6329

Reynolds S D, Reynolds P R, Pryhuber G S, Finder J D and Stripp B R 2002 Secretoglobins SCGB3A1 and SCGB3A2 define secretory cell subsets in mouse and human airways; $\mathrm{Am}$. J. Respir. Crit. Care Med. 166 1498-1509

Russo P, Warner J A, Huryk R, Perez G and Heston W D 1994 TRPM-2 gene expression in normal rat ventral prostate following castration and exposure to diethylstilbestrol, flutamide, MK-906 (finasteride), and coumarin; Prostate $\mathbf{2 4}$ 237-243

Sandford N L, Searle J W and Kerr J F 1984 Successive waves of apoptosis in the rat prostate after repeated withdrawal of testosterone stimulation; Pathology 16 406-410

Turner K J, Morley M, MacPherson S, Millar M R, Wilson J A, Sharpe R M and Saunders P T 2001 Modulation of gene expression by androgen and oestrogens in the testis and prostate of the adult rat following androgen withdrawal; Mol. Cell. Endocrinol. 178 73-87

Wan J S and Erlander M G 1997 Cloning differentially expressed genes by using differential display and subtractive hybridization; Methods Mol. Biol. 85 45-68

Warriar N, Page N, Koutsilieris M and Govindan M V 1993 Interaction of antiandrogen androgen receptor complexes with DNA and transcription activation; J. Steroid Biochem. Mol. Biol. 46 699-711

Wright A S, Douglas R C, Thomas L N, Lazier C B and Rittmaster R S 1999 Androgen-induced regrowth in the castrated rat ventral prostate: role of 5alpha-reductase; Endocrinology 140 4509-4515

Zhu X, Li H, Liu J P and Funder J W 1999 Androgen stimulates mitogen-activated protein kinase in human breast cancer cells; Mol. Cell. Endocrinol. 152 199-206

\section{MS received 17 November 2007; accepted 14 April 2008}

ePublication: 24 April 2008

Corresponding editor: Pragna I Patel 